\title{
A deep-towed magnetic survey in the southern Okinawa Trough: Implications for hydrothermal system detection
}

\author{
Wen-Bin Doo ${ }^{1, *}$, Shu-Kun Hsu ${ }^{1,2}$, Hsueh-Fen Wang ${ }^{1}$, Yin-Sheng Huang ${ }^{1}$, Ching-Hui Tsai ${ }^{1}$, \\ Chung-Liang Lo ${ }^{1}$, Shiao-Shan Lin ${ }^{1}$, Chin-Wei Liang ${ }^{1}$, and Yi-Jung Lin ${ }^{3}$ \\ ${ }^{1}$ Center for Environmental Studies, National Central University, Taoyuan City, Taiwan \\ ${ }^{2}$ Department of Earth Sciences, National Central University, Taoyuan City, Taiwan \\ ${ }^{3}$ Central Geological Survey, Ministry of Economic Affairs, Taipei City, Taiwan
}

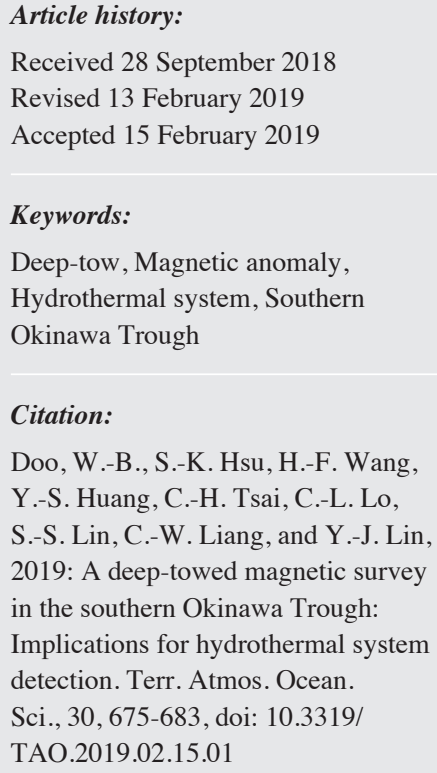

\begin{abstract}
The Okinawa Trough (OT) is widely recognized as an area with extensive volcanism and hydrothermal activity. However, finding new hydrothermal vent sites in this region remains a technical challenge due to their small sizes. A deep-towed magnetic survey can acquire short-wavelength signals, which can provide useful information on the shallow subsurface structures of hydrothermal systems. In 2017, a deep-towed magnetic survey was conducted in selected area of the southern OT. After data processing and removing the regional magnetic field, crustal magnetization map was obtained by assuming a magnetized layer with a constant thickness of $500 \mathrm{~m}$ whose top surface is the seafloor. In addition, onboard echo sounder signals (EK-60) suggest the presence of gas plumes emanating from the seafloor within the water column. Some of these emanating gas plumes are concentrated in several small areas that correlate well with magnetization lows in the study region. The deep-towed magnetic survey results and other geochemical/geophysical observation results suggest that the Geolin Mounds (GLM) site and site Penglai Fault Zone (PFZ) are the highly potential hydrothermal areas in the southern OT.
\end{abstract}

\section{INTRODUCTION}

Submarine hydrothermal vents are hot springs on the seafloor where metals are deposited co-existing special biological communities. Cold seawater penetrates percolates into a deep reaction zone and is heated to temperature $350-450^{\circ} \mathrm{C}$. This hydrothermal fluid becomes buoyant and corrosive before re-entering in the ocean. The resulting solution contains metals and large amounts of compounds such as sulfides and $\mathrm{H}_{2} \mathrm{~S}$. When this fluid is ejected out of the seafloor, it mixes with near-freezing seawater $\left(2-4^{\circ} \mathrm{C}\right)$ forming very fine-grained sulfide minerals that are deposited to form venting black (or white) smokers. These solid minerals form chimney-like structures that can reach a height of $60 \mathrm{~m}$. Recently, hydrothermal sites have attracted much attention, because hydrothermal sulfide deposits are

\footnotetext{
* Corresponding author

E-mail:wenbindoo@gmail.com
}

significantly enriched in valuable metals (Reeburgh 1982; Lowell and Rona 1985; Hannington et al. 1995).

Several previous studies (Tivey et al. 1993, 2014; Tivey and Johnson 2002; Okino et al. 2013; Fujii et al. 2015; Szitkar et al. 2015a; Honsho et al. 2016; Tao et al. 2017) have collected high-resolution magnetic data from hydrothermal fields; highlighting the correlation between low crustal magnetization with both active and extinct submarine hydrothermal vents due to hydrothermal alteration (Rona 1978; Caratori Tontini et al. 2016). In addition, Okino (2018) analyzed high resolution magnetic data which collected in two sites of different host rocks (rhyolitic and basaltic) in the southern OT. The results reveal very low magnetization in the Tarama Knoll (hosted by rhyolitic); positive magnetization caused by newly erupted lava flow and reduced magnetization caused by hydrothermal alteration in the Irabu Knoll (hosted by basaltic). Statistical analysis of sediment samples 
(ODP Leg 169) reveals that strong hydrothermal alteration can result in a complete loss of detrital/diagenetic magnetic signals, which are replaced by weaker hydrothermal signals composed of monoclinic pyrrhotite and pyrite (Urbat et al. 2000). The same conclusion of these studies is that hydrothermal alteration can reduce magnetization.

In addition, previous observations (Tivey and Johnson 2002; Okino et al. 2013; Caratori Tontini et al.2016) pointed that the horizontal scale of a submarine hydrothermal vent or alteration zone is small (typically a few hundreds of meters in diameter or less). Thus, the detection of hydrothermal vents is a technical challenge. In this study, the survey area is located in the southern OT, and the topography of the study area is between 1200 and $1600 \mathrm{~m}$ in depth (Fig. 1). Consequently, using deep-submergence vehicles are required to map the vent sites with the required resolution. According to the results of the abovementioned previous studies (Okino et al. 2013; Caratori Tontini et al. 2014; Szitkar et al. 2015b; Okino 2018), we expect that deep-towed magnetic data can provide vital information for detecting new hydrothermal systems in the southern OT.

\section{TECTONIC BACKGROUND}

A number of hydrothermal sites have been found in mid-ocean ridges and back-arc systems, including the OT, across the world. The OT is an active back-arc basin that formed behind the Ryukyu arc-trench system (Lee et al. 1980; Letouzey and Kimura 1986; Sibuet et al. 1987, 1998), where the Philippine Sea Plate is subducting beneath the Eurasian Plate. The OT extends for more than $1200 \mathrm{~km}$ from the Japanese mainland to northern Taiwan, and it is traditionally divided into three segments (northern, middle, and southern) by the Tokara Channel and Kerama Depression (Shiono et al. 1980; Kuramoto and Konishi 1989) (Fig. 1). The tectonic setting in the OT is characterized by active rifting structures and the frequent intrusion of magma, which can be expected to provide the heat received for the development of hydrothermal systems, with faults and fracture zones providing channels for hydrothermal circulation. Due to hydrothermal alteration and mineralization, back-arc hydrothermal sulfide deposits generally contain valuable metals such as $\mathrm{Zn}, \mathrm{Pb}, \mathrm{Ag}$, and $\mathrm{Au}$ (Iizasa et al. 2004). In total, 8 hydrothermal vent fields have been discovered in the OT (Watanabe and Kolima 2015) (Fig. 1).

The southern OT has the deepest topography throughout the entire OT, and it gradually narrows and ends formally at the island of Taiwan. Sibuet et al. (1998) reported on the last two extensional phases that occurred in the southwestern OT trending along $\mathrm{N} 150^{\circ}$ during the Pleistocene (2 - $0.1 \mathrm{Ma}$ ) and trending along $\mathrm{N} 170^{\circ}$ during the late Pleistocene-Holocene (0.1 - $0 \mathrm{Ma})$. The trough is filled with thick clastic sediments derived from the surrounding continents and islands together with volcaniclastic sediments associated

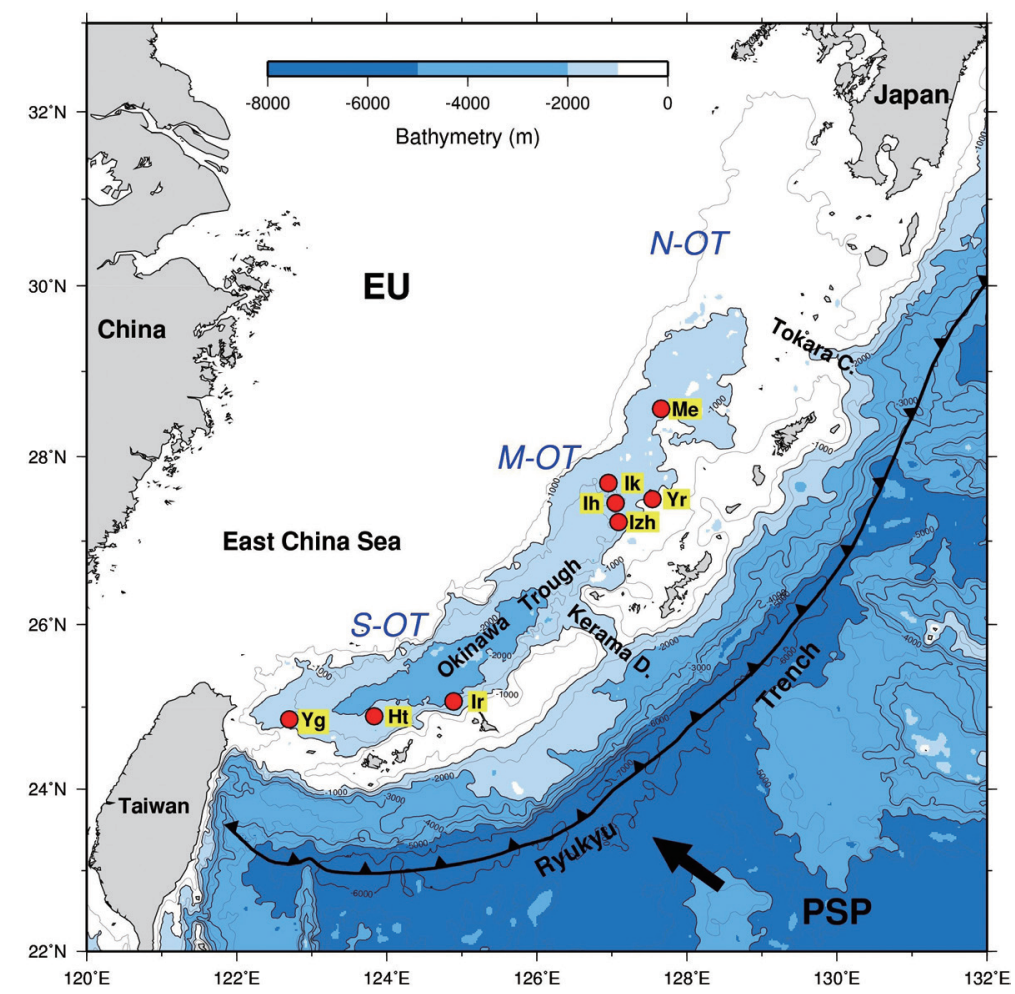

Fig. 1. Distribution of hydrothermal vent fields in the Okinawa Trough. Me: Minami-Ensei Knoll; Yr: Yoron Hole; Ik: Iheya North Knoll; Ih: Iheya Ridge; Izh: Izena Hole; Ir: Irabu Knoll; Ht: Hatoma Knoll; Yg: Daiyon-Yonaguni Knoll. 
with arc and back-arc volcanism in this area (Tsugaru et al. 1991). A volcanic lineament called the cross-back-arc volcanic trail (CBVT) (Sibuet et al. 1998; Lin et al. 2007) across the central graben and the Yonaguni Knoll (Yg) hydrothermal field which are both situated in the southern OT (Fig. 2). This represents the coexisting occurrence of zinc- and leadenriched sulfides and sulfate minerals (Suzuki et al. 2008; Ishibashi et al. 2015). To the west of the CBVT is the most pronounced back-arc basin formation area (Ishibashi et al. 2015), which contains magmatic activity-related hydrothermal venting (Tsai 1999; Lee 2005) that could constitute a highly potential for the formation of hydrothermal systems.

\section{DATA COLLECTION AND PROCESSING}

The magnetic amplitude will decrease while increasing altitude above the seafloor (Caratori Tontini et al. 2016). To examine the possibility that such small-scale hydrothermal field with a low susceptibility can be detected by magnetic surveys, the magnetic susceptibility contrast between high and low susceptibility zones was assumed to be $10 \times 10^{-4}$ S.I. Two uniform prisms with a low susceptibility are designed to be $200 \mathrm{~m}$ wide and $500 \mathrm{~m}$ thick and $100 \mathrm{~m}$ wide and 500 $\mathrm{m}$ thick. The inclination and declination of these two prisms are set to $35^{\circ}$ and $-5^{\circ}$, respectively. The magnetic anomalies at different observation levels are shown in Fig. 3. We can see that if the distance between the instrument and source is larger than $500 \mathrm{~m}$, the variations in the magnetic anomalies are too small to be detected by a magnetometer.

A high-resolution deep-towed geophysical survey was carried out in the southern OT in April 2017; the survey included a sub-bottom profiler, side-scan sonar and a proton-precession magnetometer. Magnetic data were collected along 12 NNE-SSW profiles with a total track length of $\sim 268 \mathrm{~km}$ that were spaced $\sim 500 \mathrm{~m}$ apart. The survey track lines are shown in Fig. 2. The magnetometer recorded total field geomagnetic data with a sampling interval of $1 \mathrm{~s}$, and the velocity of the vessel was approximately $2.0-2.5$ knots. The position of the instrument was calculated retrospectively using the ship position, instrument height above the seafloor and cable length. Geomagnetic data were reduced to magnetic anomalies by subtracting the Earth's regional magnetic field given by the International Geomagnetic Reference Field (IGRF-12 model). The data spectral resolution depends on the distance between the instrument and the magnetized body. Therefore, the deep-towed magnetometer generally cruised at an altitude of several tens of meters (Fig. 4a), allowing the detection of anomalies with a shorter wavelength (blue line shown in Fig. 4b). Meanwhile, we obtained the surface-towed magnetic anomalies along the

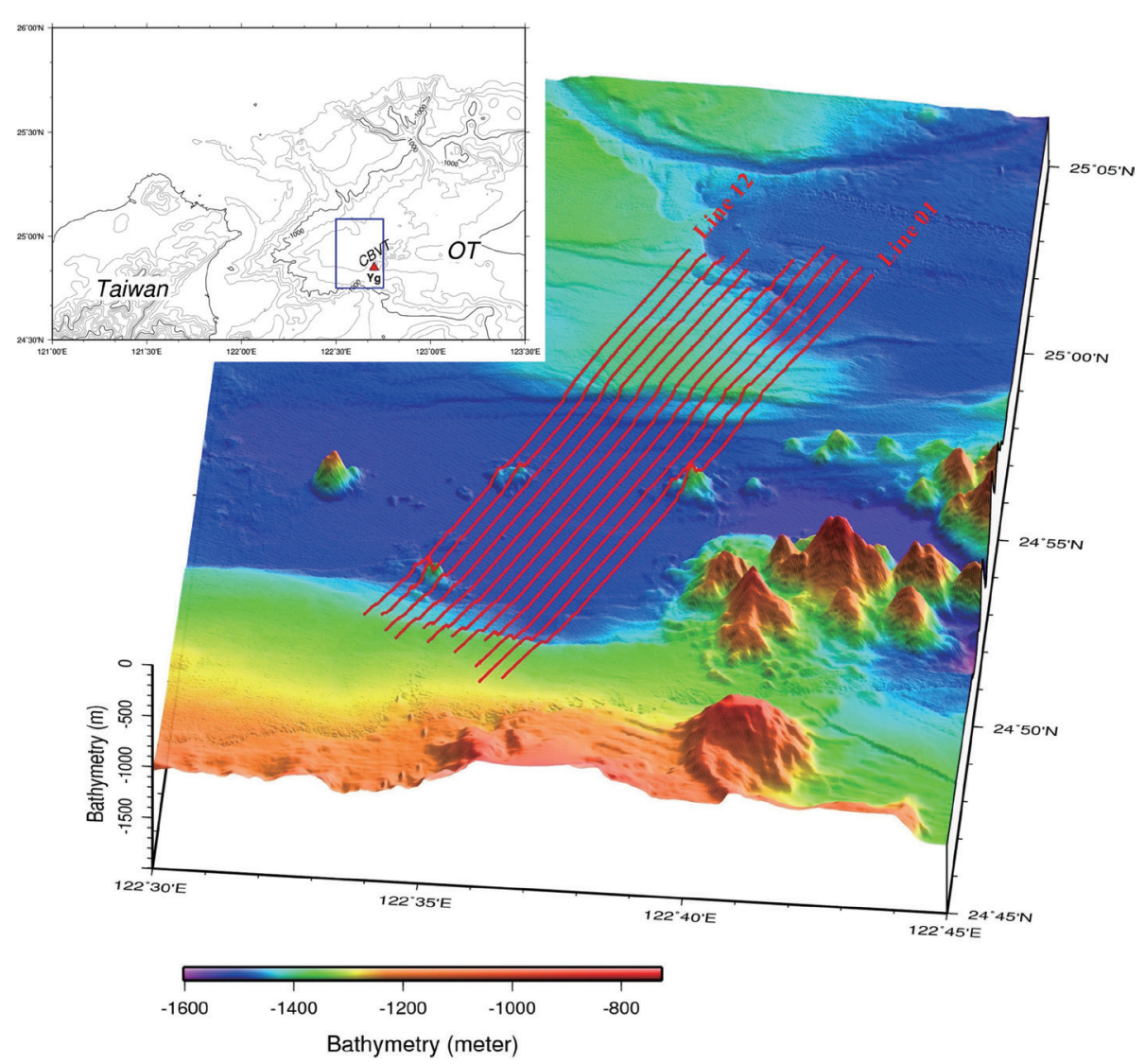

Fig. 2. Map showing the location of this study (blue frame). Red lines indicate track lines of the deep-towed magnetic survey. 
(a)
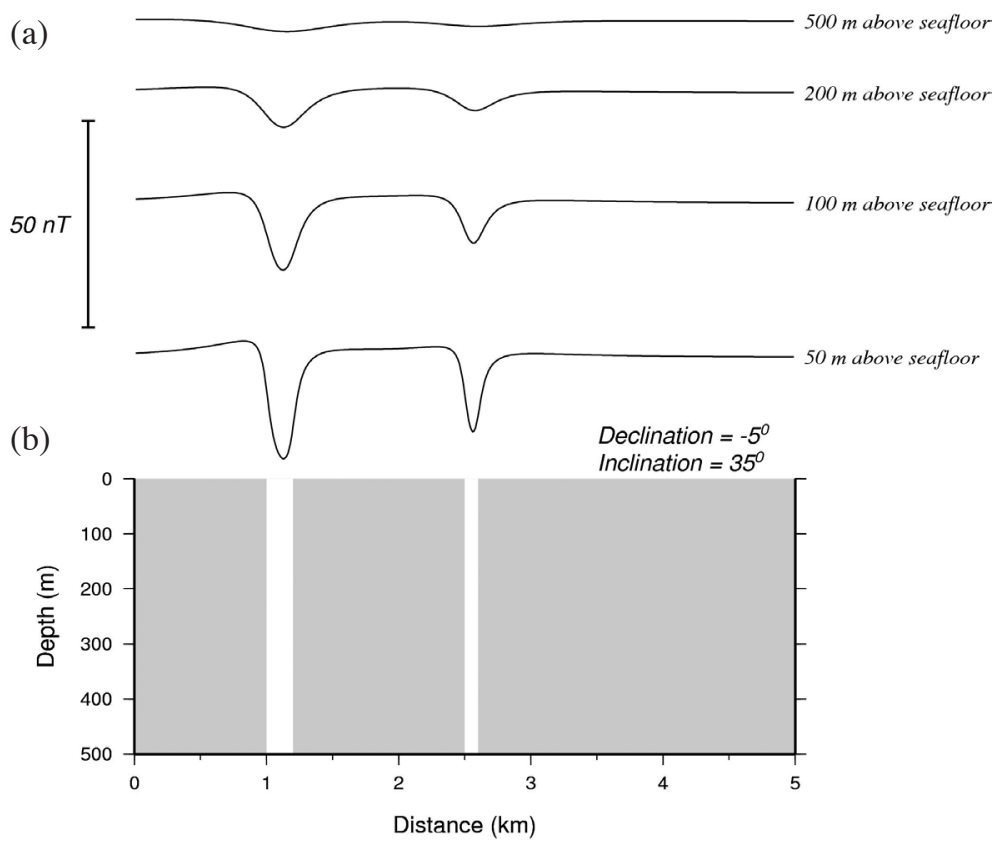

Fig. 3. Modeling magnetic anomalies caused by low magnetic susceptibility objects. (a) Curves show the observed magnetic anomalies at different observation altitude. (b) Two uniform prisms of low susceptibility are $200 \mathrm{~m}$ wide $500 \mathrm{~m}$ thick (left) and $100 \mathrm{~m}$ wide $500 \mathrm{~m}$ thick (right).
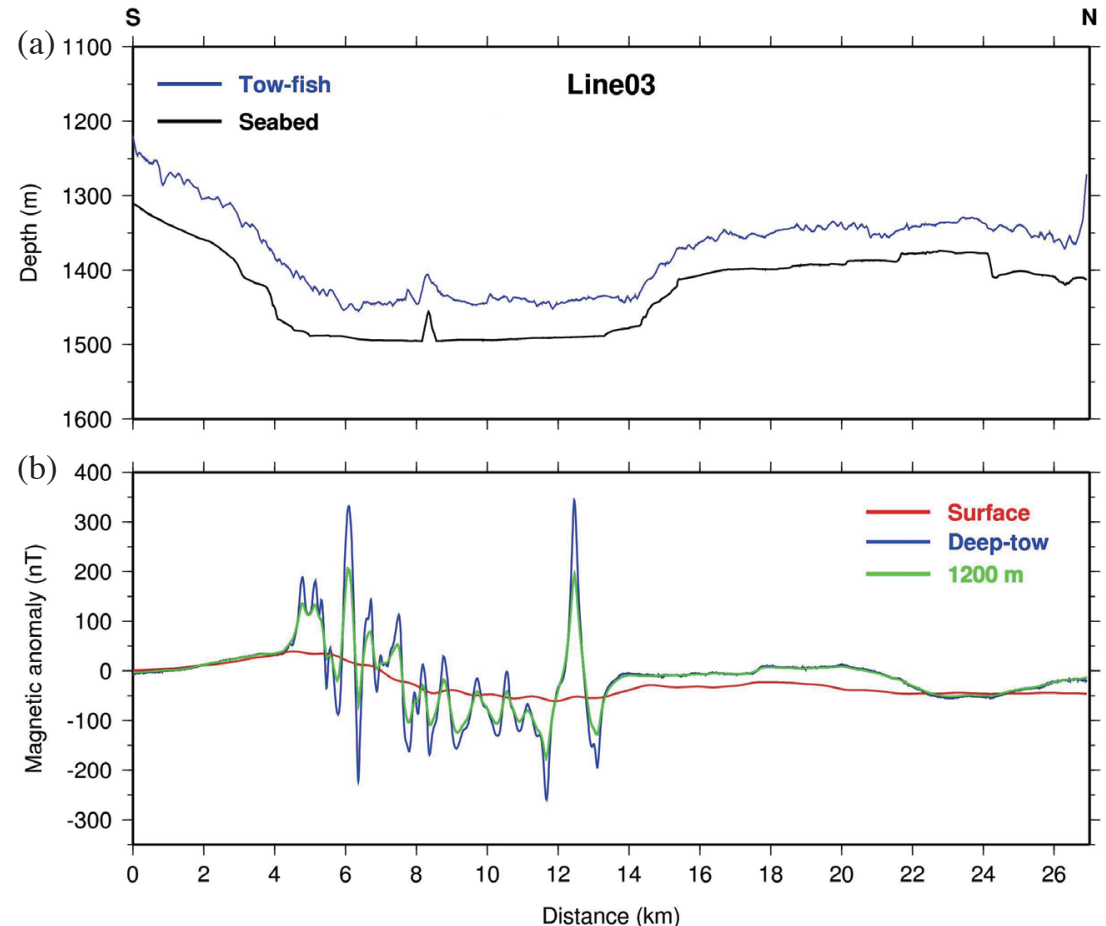

Fig. 4. (a) Line 03 topographic profile. Blue line indicates the altitude of the deep-towed instrument. (b) Magnetic anomalies along profile line 01. Red line indicates surface-towed magnetic anomalies; blue line indicates deep-towed magnetic anomalies; green line indicates observation plane at $1200 \mathrm{~m}$ depth magnetic anomalies. 
same profiles from Doo et al. (2015) dataset. As shown in Fig. 4b (red line), the variation in the surface-towed magnetic anomalies is small, which roughly reveals longwavelength regional structural signals. For the convenience of data analysis, a fixable observation level is necessary. A correction for the instrument altitude above the seafloor was performed by upward continuation technique (Ciminale and Loddo 1989; Blakely 1995) from the uneven observation plane to a level plane at a depth of $1200 \mathrm{~m}$ (green line shown in Fig. 4b). After data processing, we obtained a magnetic anomaly map, as shown in Fig. 5.

To minimize edge effects, the deep-towed magnetic data were bordered with surface magnetic data (Doo et al. 2015) that had been downward continued to the level plane at a depth of $1200 \mathrm{~m}$. Then, before calculating the crustal magnetization, a bandpass filter with wavelength cutoffs of 10 and $0.1 \mathrm{~km}$ and a pass-band from $5-0.5 \mathrm{~km}$ were

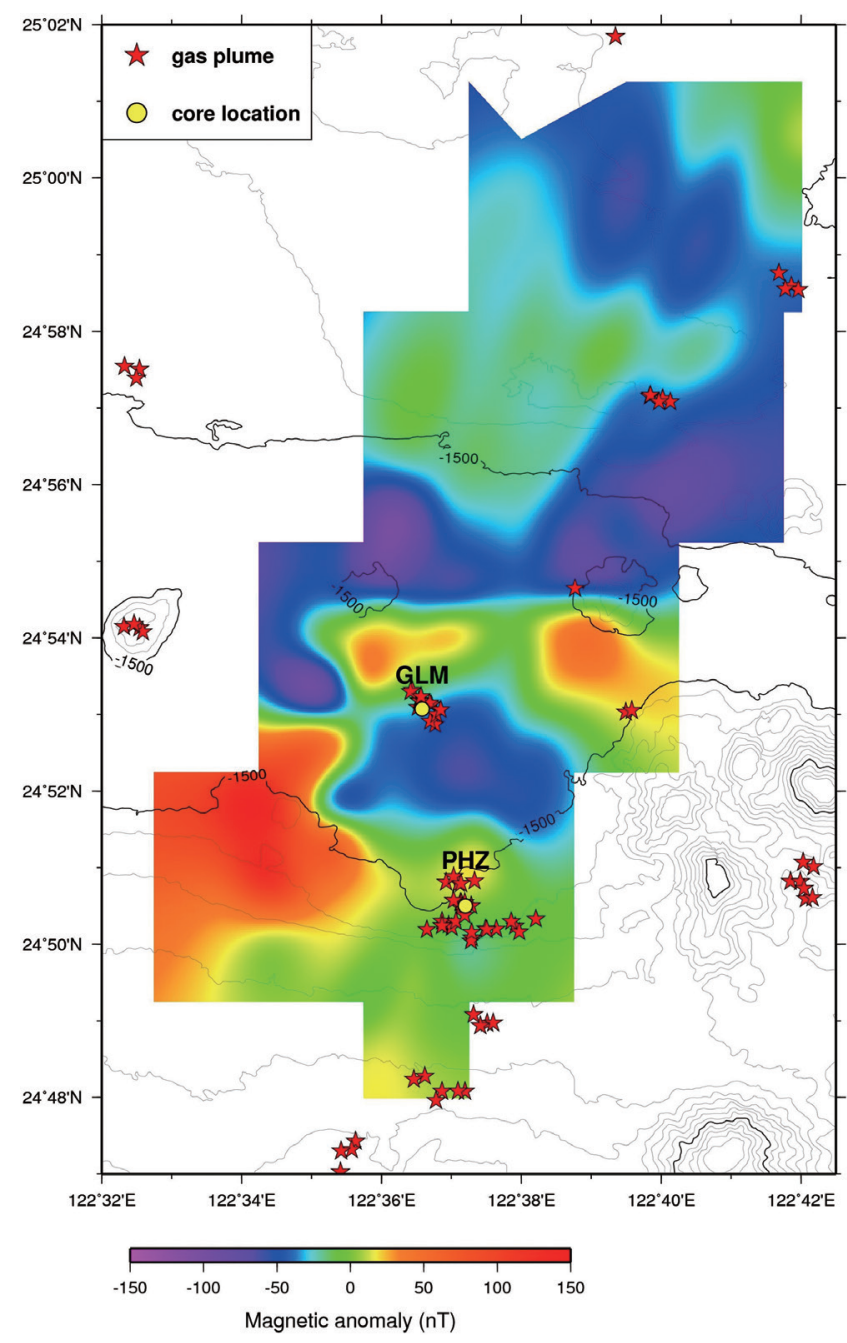

Fig. 5. Magnetic anomaly map of the study area. Red stars indicate gas plumes locations identified by EK-60 system. Yellow circles indicate the location of gravity code sites. Black and gray lines indicate bathymetric contours. GLM: Geolin Mounds; PFZ: Penglai Fault Zone. used to ensure the convergence of the solution. In order to obtain the equivalent magnetization map in the study area, we have performed a magnetic inversion (Hsu et al. 2001). We assumed that the magnetic anomalies were attributed to an equivalent layer with a constant thickness of $500 \mathrm{~m}$ and that the top of each block was the seafloor. The magnetization direction was assumed to be the same as the presentday geomagnetic field (the inclination is set to $36.8^{\circ}$ and the declination is set to $-4.5^{\circ}$ based on the IGRF- 12 model). The equivalent magnetization of each block was obtained by inverting the magnetic data using the least-square method (Menke 1984), and the inversion calculation is accomplished using the LSQR algorithm (Paige and Saunders 1982). The resulting magnetization map is shown in Fig. 6.

In addition, single-beam bathymetry data were collected in the southern OT during 2016 - 2018 using the onboard echo sounder (EK-60 system) mounted on the R/Vs OR1

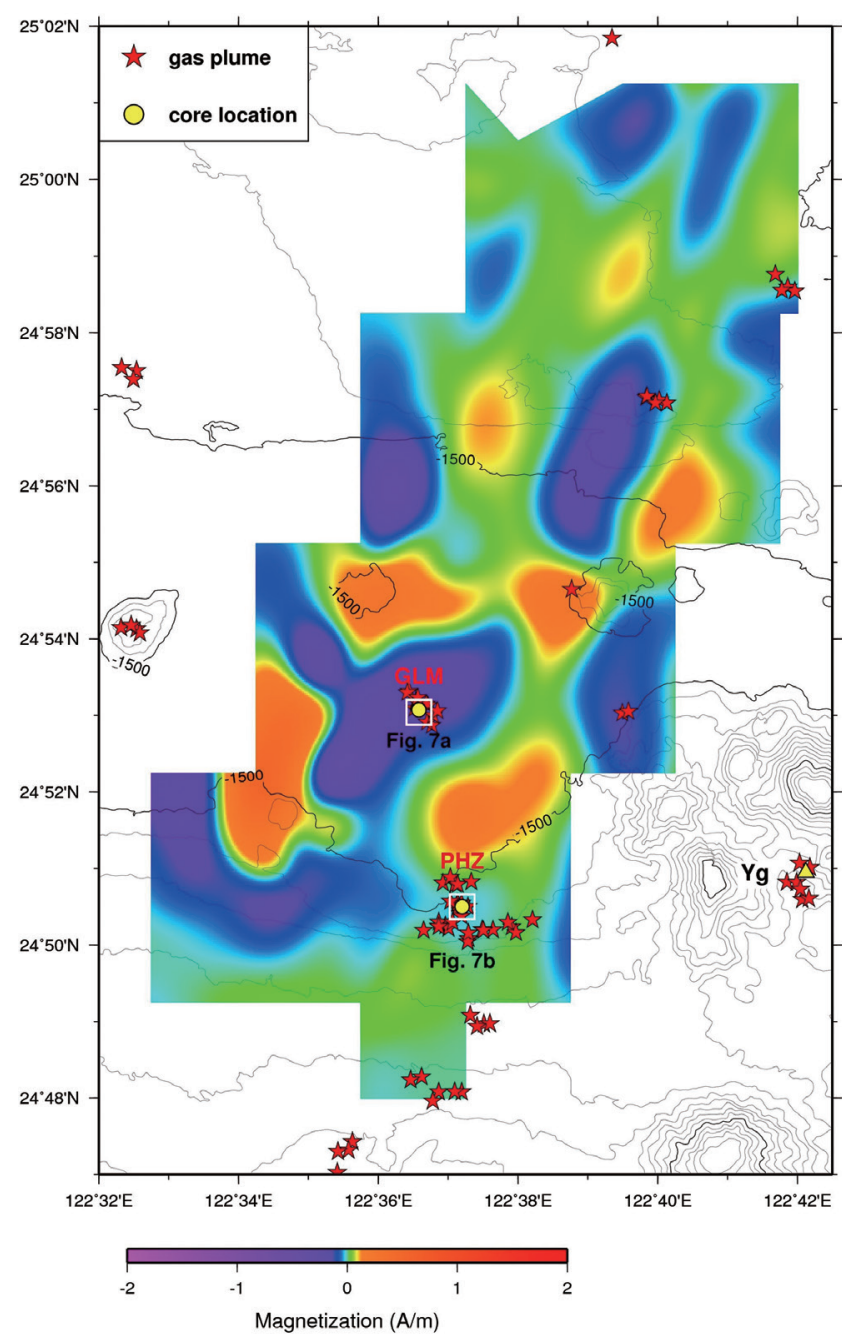

Fig. 6. Magnetization distribution map of the study area. Red stars indicate gas plumes locations identified by EK-60 system. Yellow circles indicate the location of gravity code sites. Black and gray lines indicate bathymetric contours. GLM: Geolin Mounds; PFZ: Penglai Fault Zone; Yg (yellow triangle): Yonaguni Knoll. 
and OR2. The EK-60 system is useful for several investigations in the water column, including those conducted to determine fish distributions and marine creature activity, and for fields as ocean physics, marine geology and geophysics. Gases or bubbles can be detected in terms of gas flares or gas plumes in the water column. Venting is an obvious feature of hydrothermal fields. Thus, if gas flares (or plumes) in the seawater column are emitted persistently from the seafloor, they can be detected using the EK-60 system. In terms of the features of hydrothermal fields, the onboard EK-60 system could represent a relatively quick and economic tool for elementary investigations. Furthermore, geophysical, geological, and geochemical observation results in the study area are integrated for detecting new hydrothermal systems.

\section{RESULTS AND DISCUSSION}

Previous studies have shown that the OT lacks oceanic lithosphere (Nagumo et al. 1986; Hirata et al. 1991; Oshida et al. 1992), and a recent seismic study revealed a minimum crustal thickness of $8 \mathrm{~km}$ at the southernmost part (Klingelhoefer et al. 2009). Although this thickness might be thin compared with typical continental crust, the velocity gradient of the layer is too low to be interpreted as oceanic crust (Ishibashi et al. 2015). The nature of the crust in the southern OT suggests the presence of extended continental crust. Consequently, no magnetic reversals have occurred in the study area, and the equivalent magnetization patterns could actually reflect the magnetic characteristics of subsurface materials. Thus, some small areas in Fig. 6 with magnetization lows could reflect the characteristics of shallow subsurface materials. A number of studies have reported that hydrothermal systems are typically associated with low magnetization. However, some other factors may also result in this type of magnetic feature. To ensure that these magnetization lows are related to hydrothermal systems, we need to compare their characteristics with other geophysical, geological, and geochemical observations.

The EK-60 system detected several gas plumes in the study area (Hsu 2017; Tsai et al. 2019), some of which were concentrated in several small areas that correlate well with magnetization lows (Fig. 6). Geochemical investigation results reveal that high methane concentrations, high $\mathrm{He}$ isotope ratios, and high ${ }^{3} \mathrm{He} /{ }^{4} \mathrm{He}$ ratios (Su 2017) were observed at both site GLM and site PFZ. Furthermore, active hydrothermal vent images were found around site GLM (observed by a Fiber-optical Instrumentation Towed System) and mineral deposits with metallic reflections were observed around site P1 (Chen 2017; Chou et al. 2019). Apparently, the locations of sites GLM and PFZ both coincide with magnetization lows and gas plumes. Furthermore, gas escape features are observed from the high-resolution deeptowed side-scan sonar images (Fig. 7) (Hsu 2017). All of these results indicate intense hydrothermal activity at these (a)
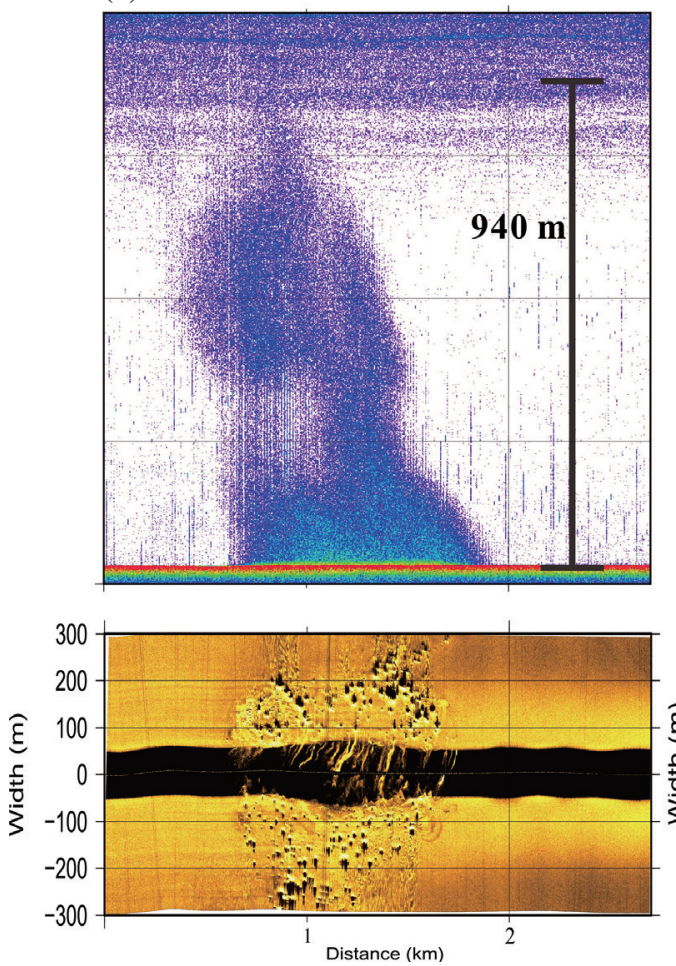

(b)
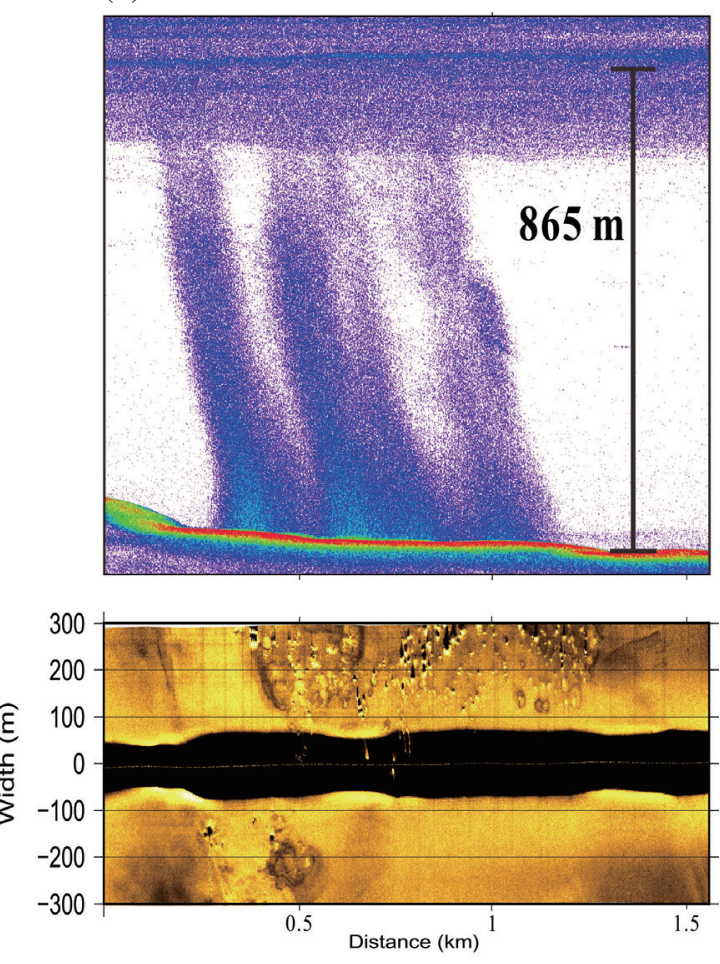

Fig. 7. (a) EK-60 echo sounder image (upper panel) and side-scan sonar image (lower panel) around site GLM in Fig. 6. (b) EK-60 echo sounder image (upper panel) and side-scan sonar image (lower panel) around site PFZ in Fig. 6. 
two sites (GLM and PFZ), although additional, more detailed investigations are needed.

Several obvious features such as fluid emanations, high heat-flows, and high ${ }^{3} \mathrm{He} /{ }^{4} \mathrm{He}$ ratios could be the useful indicators for detecting hydrothermal systems. However, if a hydrothermal system is inactive (or extinct), these features may not exist. In terms of the exploration for metalliferous ore resources, both active and extinct hydrothermal vent sites are important. The reduced magnetization characteristics are still preserved after the cessation of hydrothermal venting (Tivey and Johnson 2002). Thus, we can detect inactive hydrothermal fields based on high-resolution deeptowed magnetic surveys.

\section{CONCLUSION}

Compared with a surface-towed magnetic survey, deep-towed magnetic data contain short-wavelength signals (Fig. 4) that can provide the opportunity to image shallow, small subsurface structures. In terms of the detection of hydrothermal systems, therefore, near-bottom surveys are indeed necessary. Our observation results reveal strong correlations between magnetization lows and some hydrothermal system-associated features, such as gas plumes, high heat flow, and high ${ }^{3} \mathrm{He} /{ }^{4} \mathrm{He}$ ratios (Fig. 6). These results are consistent with several previous near-bottom magnetic studies. However, some areas have magnetization lows but do not reveal other hydrothermal features, and thus, they need to be investigated further. Combining the geochemical and geophysical investigation results in the study area, we propose that the GLM site and site PFZ are the highly potential hydrothermal areas in the southern OT. Consequently, additional investigations would be worthwhile.

Acknowledgements Constructive reviews from Dr. F.C. Tontini and one anonymous reviewer are appreciated. We thank the crew of the R/Vs OR1 and OR2 for their efforts in collecting deep-towed magnetic and EK-60 data. This study was conducted as an investigation of mineral resource project funded by the Central Geological Survey, Ministry of Economic Affairs, Taiwan. Most of the figures are generated using the GMT software of Wessel and Smith (1998).

\section{REFERENCES}

Blakely, R. J., 1995: Potential Theory in Gravity and Magnetic Applications, Cambridge University Press, Cambridge, U.K., doi: 10.1017/CBO9780511549816. [Link]

Caratori Tontini, F., G. Bortoluzzi, C. Carmisciano, L. Cocchi, C. E. J. de Ronde, M. Ligi, and F. Muccini, 2014: Near-Bottom Magnetic Signatures of Submarine Hydrothermal Systems at Marsili and Palinuro Volcanoes, Southern Tyrrhenian Sea, Italy. Econ. Geol., 109,
2119-2128, doi: 10.2113/econgeo.109.8.2119. [Link]

Caratori Tontini, F., T. J. Crone, C. E. J. de Ronde, D. J. Fornari, J. C. Kinsey, E. Mittelstaedt, and M. Tivey, 2016: Crustal magnetization and the subseafloor structure of the ASHES vent field, Axial Seamount, Juan de Fuca Ridge: Implications for the investigation of hydrothermal sites. Geophys. Res. Lett., 43, 6205-6211, doi: 10.1002/2016GL069430. [Link]

Chen, H.-H., 2017: Seafloor imaging and sampling in the southern Okinawa Trough (2/4). Report of Central Geological Survey, 106-14-B, 156 pp. (in Chinese with English abstract)

Chou, Y.-C., C.-C. Wang, H.-H. Chen, and Y.-H. Lin, 2019: Seafloor characterization in the southernmost Okinawa Trough from underwater optical imagery. Terr. Atmos. Ocean. Sci., 30, 717-737, doi: 10.3319/ TAO.2019.03.14.01. [Link]

Ciminale, M. and M. Loddo, 1989: A computer program to perform the upward continuation of potential field data between arbitrary surfaces. Comput. Geosci., 15, 889-903, doi: 10.1016/0098-3004(89)90003-4. [Link]

Doo, W.-B., S.-K. Hsu, and L. Armada, 2015: New magnetic anomaly map of the East Asia with some preliminary tectonic interpretations. Terr. Atmos. Ocean. Sci., 26, 73-81, doi: 10.3319/TAO.2014.08.19.07(GRT). [Link]

Fujii, M., K. Okino, C. Honsho, J. Dyment, F. Szitkar, N. Mochizuki, and M. Asada, 2015: High-resolution magnetic signature of active hydrothermal systems in the back-arc spreading region of the southern Mariana Trough. J. Geophys. Res., 120, 2821-2837, doi: 10.1002/2014JB011714. [Link]

Hannington, M. D., I. R. Jonasson, P. M. Herzig, and S. Petersen, 1995: Physical and chemical processes of seafloor mineralization at mid-ocean ridges. In: Humphris, S. E., R. A. Zierenberg, L. S. Mullineaux, and R. E. Thomson (Eds.), Seafloor Hydrothermal Systems: Physical, Chemical, Biological, and Geological Interactions, Volume 91, American Geophysical Union, 115-157, doi: 10.1029/GM091p0115. [Link]

Hirata, N., H. Kinoshita, H. Katao, H. Baba, Y. Kaiho, S. Koresawa, Y. Ono, and K. Hayashi, 1991: Report on DELP 1988 cruises in the Okinawa Trough: Part 3. Crustal structure of the southern Okinawa Trough. Bull. ERI Univ. Tokyo, 66, 37-70.

Honsho, C., T. Ura, K. Kim, and A. Asada, 2016: Postcaldera volcanism and hydrothermal activity revealed by autonomous underwater vehicle surveys in Myojin Knoll caldera, Izu-Ogasawara arc. J. Geophys. Res., 121, 4085-4102, doi: 10.1002/2016JB012971. [Link]

Hsu, S.-K., 2017: Geological Investigation of Mineral Resource Potential in the Offshore Northeastern Taiwan: High-resolution Sonar and Magnetic Surveys (2/4). Report of Central Geological Survey, 106-13, 237 pp. (in Chinese with English abstract) 
Hsu, S.-K., J.-C. Sibuet, and C.-T. Shyu, 2001: Magnetic inversion in the East China Sea and Okinawa Trough: Tectonic implications. Tectonophysics, 333, 111-122, doi: 10.1016/S0040-1951(00)00270-5. [Link]

Iizasa, K., M. Sasaki, K. Matsumoto, S. Shiokawa, M. Tanahashi, and onboard scientists, 2004: A first extensive hydrothermal field associated with Kurokotype deposit in a Silicic Submarine caldera in a Nascent Rift Zone, Izu-Ogasawara (Bonin) arc, Japan. Oceans '04 MTS/IEEE Techno-Ocean '04 (IEEE Cat. No.04CH37600), IEEE, Kobe, Japan, 991-996, doi: 10.1109/OCEANS.2004.1405638. [Link]

Ishibashi, J., F. Ikegami, T. Tsuji, and T. Urabe, 2015: Hydrothermal activity in the Okinawa Trough back-arc basin: Geological background and hydrothermal mineralization. In: Ishibashi, J., K. Okino, and M. Sunamura (Eds.), Subseafloor Biosphere Linked to Hydrothermal Systems: TAIGA Concept, Springer, Tokyo, 337-359, doi: 10.1007/978-4-431-54865-2_27. [Link]

Klingelhoefer, F., C.-S. Lee, J.-Y. Lin, and J.-C. Sibuet, 2009: Structure of the southernmost Okinawa Trough from reflection and wide-angle seismic data. Tectonophysics, 466, 281-288, doi: 10.1016/j.tecto.2007.11.031. [Link]

Kuramoto, S. and K. Konishi, 1989: The southwest Ryukyu arc is a migrating microplate (forearc sliver). Tectonophysics, 163, 75-91, doi: 10.1016/00401951(89)90119-4. [Link]

Lee, C.-S., G. G. Shor, L. D. Bibee, R. S. Lu, and T. W. C. Hilde, 1980: Okinawa Trough: Origin of a back-arc basin. Mar. Geol., 35, 219-241, doi: 10.1016/00253227(80)90032-8. [Link]

Lee, Y.-L., 2005: Investigation of the submarine volcanoes and hydrothermal vents in the offshore northeastern Taiwan. Master Thesis, National Taiwan Ocean University, Keelung City, Taiwan, 44 pp. (in Chinese)

Letouzey, J. and M. Kimura, 1986: The Okinawa Trough: Genesis of a back-arc basin developing along a continental margin. Tectonophysics, 125, 209-230, doi: 10.1016/0040-1951(86)90015-6. [Link]

Lin, J.-Y., J.-C. Sibuet, C.-S. Lee, S.-K. Hsu, and F. Klingelhoefer, 2007: Origin of the southern Okinawa Trough volcanism from detailed seismic tomography. J. Geophys. Res., 112, B08308, doi: 10.1029/2006JB004703. [Link]

Lowell, R. P. and P. A. Rona, 1985: Hydrothermal models for the generation of massive sulfide ore deposits. J. Geophys. Res., 90, 8769-8783, doi: 10.1029/ JB090iB10p08769. [Link]

Menke, W., 1984: Geophysical Data Analysis: Discrete Inverse Theory, Academic Press, London, 272 pp, doi: 10.1016/B978-0-12-490920-5.X5001-7. [Link]

Nagumo, S., H. Kinoshita, J. Kasahara, T. Ouchi, H.
Tokuyama, T. Asanuma, S. Koresawa, and H. Akiyoshi, 1986: Report on DELP 1984 cruises in the middle Okinawa Trough Part 2: Seismic structural studies. Bull. ERI Univ. Tokyo, 61, 167-202.

Okino, K., 2018: Two contrasting hydrothermal fields in the Southern Okinawa Trough. 2018 IONTU-AORI Workshop, Taipei, Taiwan.

Okino, K., K. Nakamura, Y. Nogi, M. Fujii, N. Mochizuki, M. Asada, and C. Honsho, 2013: Discovery and characterization of a new hydrothermal vent based on magnetic and acoustic surveys. 2013 IEEE International Underwater Technology Symposium (UT), IEEE, Tokyo, Japan, 5 pp, doi: 10.1109/UT.2013.6519827. [Link]

Oshida, A., K. Tamaki, and M. Kimura, 1992: Origin of the magnetic anomalies in the southern Okinawa Trough. J. Geomagn. Geoelectr., 44, 345-359, doi: 10.5636/ jgg.44.345. [Link]

Paige, C. C. and M. A. Saunders, 1982: LSQR: An algorithm for sparse linear equations and sparse least squares. ACM Trans. Math. Software, 8, 43-71, doi: 10.1145/355984.355989. [Link]

Reeburgh, W. S., 1982: "Active" and "passive" hydrothermal systems in the oceanic crust: Predicted physical conditions. In: Fanning, K. A. and F. T. Manheim (Eds.), The Dynamic Environment of the Ocean Floor, Lexington Books, 441-470.

Rona, P. A., 1978: Magnetic signatures of hydrothermal alteration and volcanogenic mineral deposits in oceanic crust. J. Volcanol. Geotherm. Res., 3, 219-225, doi: 10.1016/0377-0273(78)90010-0. [Link]

Shiono, K., T. Mikumo, and Y. Ishikawa, 1980: Tectonics of the Kyushu-Ryukyu Arc as evidenced from seismicity and focal mechanism of shallow to intermediate-depth earthquakes. J. Phys. Earth, 28, 17-43, doi: 10.4294/ jpe 1952.28.17. [Link]

Sibuet, J.-C., J. Letouzey, F. Barbier, J. Charvet, J.-P. Foucher, T. W. C. Hilde, M. Kimura, L.-Y. Chiao, B. Marsset, C. Muller, and J.-F. Stéphan, 1987: Back arc extension in the Okinawa Trough.J. Geophys.Res., 92, 14041-14063, doi: 10.1029/JB092iB13p14041. [Link]

Sibuet, J.-C., B. Deffontaines, S.-K. Hsu, N. Thareau, J. P. Le Formal, C.-S. Liu, and ACT party, 1998: Okinawa Trough backarc basin: Early tectonic and magmatic evolution. J. Geophys. Res., 103, 30245-30267, doi: 10.1029/98JB01823. [Link]

Su, C.-C., 2017: Geochemical investigation in the southern Okinawa Trough (2/4). Report of Central Geological Survey, 106-14-A, 223 pp. (in Chinese with English abstract)

Suzuki, R., J.-I. Ishibashi, M. Nakaseama, U. Konno, U. Tsunogai, K. Gena, and H. Chiba, 2008: Diverse range of mineralization induced by phase separation of hydrothermal fluid: Case study of the Yonaguni Knoll IV 
hydrothermal field in the Okinawa Trough Back-arc Basin.Resour.Geol., 58, 267-288, doi: 10.1111/j.17513928.2008.00061.x. [Link]

Szitkar, F., J. Dyment, Y. Fouquet, Y. Choi, and C. Honsho, 2015a: Absolute magnetization of the seafloor at a basalt-hosted hydrothermal site: Insights from a deepsea submersible survey. Geophys. Res. Lett., 42, 10461052, doi: 10.1002/2014GL062791. [Link]

Szitkar, F., S. Petersen, F. C. Tontini, and L. Cocchi, 2015b: High-resolution magnetics reveal the deep structure of a volcanic-arc-related basalt-hosted hydrothermal site (Palinuro, Tyrrhenian Sea). Geochem. Geophys. Geosyst., 16, 1950-1961, doi: 10.1002/2015GC005769. [Link]

Tao, C., T. Wu, C. Liu, H. Li, and J. Zhang, 2017: Fault inference and boundary recognition based on near-bottom magnetic data in the Longqi hydrothermal field. Mar. Geophys. Res., 38, 17-25, doi: 10.1007/s11001016-9283-2. [Link]

Tivey, M. A. and H. P. Johnson, 2002: Crustal magnetization reveals subsurface structure of Juan de Fuca Ridge hydrothermal vent fields. Geology, 30, 979-982, doi: 10.1130/0091-7613(2002)030<0979:CMRSSO > 2.0. CO;2. [Link]

Tivey, M. A., P. A. Rona, and H. Schouten, 1993: Reduced crustal magnetization beneath the active sulfide mound, TAG hydrothermal field, Mid-Atlantic Ridge at $26^{\circ}$ N. Earth Planet. Sci. Lett., 115, 101-115, doi: 10.1016/0012-821X(93)90216-V. [Link]

Tivey, M. A., H. P. Johnson, M. S. Salmi, and M. Hutnak, 2014: High-resolution near-bottom vector magnetic anomalies over Raven Hydrothermal Field, Endeavour Segment, Juan de Fuca Ridge. J. Geophys. Res., 119, 7389-7403, doi: 10.1002/2014JB011223. [Link]

Tsai, C.-H., 1999: Investigation of the submarine volcanoes and hydrothermal activity in the southern Okinawa Trough. Master Thesis, National Taiwan Ocean University, Keelung City, Taiwan. (in Chinese)

Tsai, C.-H., S.-K. Hsu, Y.-F. Chen, H.-S. Lin, S.-Y. Wang, S.-C. Chen, C.-W. Liang, and Y.-Y. Cho, 2019: Gas plumes and near-seafloor bottom current speeds of the southernmost Okinawa Trough determined from echo sounders. Terr. Atmos. Ocean. Sci., 30, 649-674, doi: 10.3319/TAO.2019.07.07.01. [Link]

Tsugaru, R., Y. Tamaki, M. Sato, M. Kimura, and K. Shimamura, 1991: Report on DELP 1998 cruises in the Okinawa Trough: Part 4, Preliminary report on the sediment samples. Bull. Earthquake Res. Inst., 66, 71-89.

Urbat, M., M. J. Dekkers, and K. Krumsiek, 2000: Discharge of hydrothermal fluids through sediment at the Escanaba Trough, Gorda Ridge (ODP Leg 169): Assessing the effects on the rock magnetic signal. Earth Planet. Sci. Lett., 176, 481-494, doi: 10.1016/S0012821X(00)00024-8. [Link]

Watanabe, H. and S. Kolima, 2015: Vent fauna in the Okinawa Trough. In: Ishibashi J., K. Okino, and M. Sunamura (Eds.), Subseafloor Biosphere Linked to Hydrothermal Systems: TAIGA Concept, Springer, Tokyo, 449-459, doi: 10.1007/978-4-431-54865-2_34. [Link]

Wessel, P. and W. H. F. Smith, 1998: New, improved version of generic mapping tools released. Eos, Trans. $A G U, 79,579$, doi: 10.1029/98EO00426. [Link] 